\title{
Reflexões sobre o Presente e o Futuro da Formação Médica em Macau
}

\section{Reflections on the Present and Future of Medical Training in Macau}

\author{
Mónica PON $\square^{1,2,3}$ \\ Acta Med Port 2019 Nov;32(11):681-682 - https://doi.org/10.20344/amp.12869
}

Palavras-chave: Educação Médica; Macau

Keywords: Education, Medical; Macau

Sou especialista em Medicina Interna no Centro Hospitalar Conde São Januário (CHCSJ) em Macau onde cheguei há cerca de três anos e meio.

O impacto que senti na área da formação médica deriva desde logo da inexistência de uma Faculdade de Medicina e de uma estrutura como a Ordem dos Médicos (OM) em Portugal.

A formação pré-graduada em Medicina é maioritariamente adquirida na República Popular da China (RPC), mais precisamente na vizinha província de Cantão nas Universidades de Jinan e Sun Yat-Sen. Outros candidatos decidem-se por Universidades situadas em Xangai ou Pequim, e uma minoria opta pelas Universidades Portuguesas ou outras localizadas no Reino Unido ou Austrália. Após a licenciatura, a progressão na carreira faz-se numa estrutura herdada do sistema Português, passando pelo ano do Internato do Ano Comum, Internato Complementar e para quem opte por seguir a carreira pública: Assistente Hospitalar, Consultor (integrado como categoria na carreira) e Chefe de Serviço Hospitalar. O regime da carreira médica encontra-se publicado no Boletim Oficial de Macau, decreto lei n. 10/2010.1

Esta diversidade confere uma base muito heterogénea na formação médica e consequentemente na qualidade dos jovens médicos, que depois urge harmonizar no terreno, tarefa nem sempre fácil de se atingir com a desejada eficácia. Tal estará também na origem da reduzida produção científica, em particular a dirigida a revistas médicas com fator de impacto.

Macau faz parte integrante da República Popular da China, usufruindo de um regime de autonomia especial, tal como Hong Kong, o qual se prolongará até que se completem os 50 anos da transição para a RPC, celebrada em Dezembro de 1999. É relevante relembrar que o Português, a par do Cantonês, é também língua oficial no território, embora com pouca expressão na maioria da população, onde o Inglês surge a seguir à língua chinesa. A língua inglesa é também a usada no pessoal da área da saúde, sendo a língua de comunicação profissional, sem dúvida a mais usada nos registos clínicos e nas sessões científicas.

Com cerca de 600 mil residentes, Macau recebe por ano mais de 35 milhões de turistas, maioritariamente vindos da RPC, atraídos pela indústria do jogo em Macau. ${ }^{2}$ Esta presença massiva tem necessariamente impacto na vida de Macau, nomeadamente no que concerne ao recurso aos serviços de saúde, facilmente percecionado por quem visita o hospital.

O Serviço Público assenta num hospital inaugurado há 145 anos, na altura como hospital militar, objecto de várias intervenções ao longo dos anos. Hoje em dia, é um centro hospitalar com cerca de 900 camas e razoavelmente bem equipado, complementando uma rede de Cuidados Primários com oito centros e três postos de saúde. A diferença entre centros e postos de saúde reside apenas no tamanho e na ausência de alguns serviços, nomeadamente Medicina Tradicional Chinesa. Tanto os cuidados diferenciados hospitalares como os cuidados primários foram merecedores de acreditação hospitalar concedidos pelo Australian Council on Healthcare Standards - $(\mathrm{ACHS}) .{ }^{2}$

A Medicina privada assenta em dois hospitais e uma vasta rede de clínicas e consultórios onde a Medicina Tradicional Chinesa (MTC) tem também um peso importante. O Hospital Kiang Wu, fundado em 1871 é o mais antigo. Foi aí que trabalhou o fundador da República da China Sun Yat-Sen, também médico, que trouxe para esse hospital a prática da medicina ocidental. Outro mais recente, o Hospital Universitário de Ciência e Tecnologia - mais conhecido pela sigla em inglês MUST — é o hospital onde se alberga a Faculdade de Medicina de Macau. ${ }^{3}$

No decorrer deste texto, assinalo o que no meu ponto de vista poderá ser o turning point no capítulo da formação médica em Macau.

Em julho, foi publicamente inaugurada a Academia Médica de Macau (AMM), criada por Decreto-Lei a 03 de outubro de 2018. Esta entidade irá incluir as competências que em Portugal são atribuídas à OM, no que diz respeito ao reconhecimento de especialistas que queiram vir

1. Departamento de Medicina Interna. Centro Hospitalar Conde São Januário. Macau.

2. Equipa de Supervisão da Formação Médica. Academia Médica de Macau. Macau

3. Associação dos Médicos de Língua Portuguesa de Macau. Macau.

$\triangle$ Autor correspondente: Mónica Pon. monicapon76@gmail.com

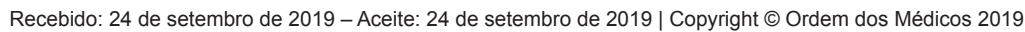


trabalhar no território, para além de funções relacionadas com a formação. ${ }^{4}$ A AMM tem como objetivo responsabilizar-se pela formação profissional médica bem como pela organização, coordenação e supervisão dos internatos médicos dotados de autonomia científica e pedagógica. Antes da criação da AMM o Internato Médico era regulado pela Direção do Internato Médico dos Serviços de Saúde de Macau e regulamentado pelo Decreto-Lei n. ${ }^{\circ}$ 17/88/M, publicado no Boletim Oficial de Macau. ${ }^{5}$

Outra das competências da Academia Médica de Macau será o estímulo para a investigação e publicação científica que até à data tem sido escassa. Eventualmente, poderão ser atribuídos prémios para as melhores publicações científicas e apoios para participações em congressos internacionais para aqueles que levem trabalhos para serem apresentados, quer seja sob a forma de poster ou comunicação oral. Poderão também ser dados incentivos para a publicação de artigos aceites em revistas científicas.

No dia 6 de setembro de 2019 teve início o primeiro ano do curso de Medicina em Macau, ministrado em Inglês, e com parcerias que privilegiam universidades portuguesas nomeadamente a de Lisboa e do Porto com as quais foram assinados protocolos de cooperação que poderão traduzirse no intercâmbio de estudantes no futuro.

O internato complementar (IC) foi recentemente reformulado tendo uma duração de seis anos dividido em duas etapas, a primeira de três anos de treino básico com rotação por diferentes serviços e os restantes três de treino avançado, já inserido na especialidade escolhida. Este modelo, inspirado no que se pratica em Hong Kong, vem traduzir a pressão que a escola médica de influência portuguesa vai sentir perante a anglo saxónica (HK) e inevitavelmente a da RPC no futuro que se avizinha. Um exemplo notório, para além do programa de formação do internato complementar, é o recurso a especialistas de HK para a constituição do júri nos exames de saída de especialidade e nos concursos de progressão de carreira na função pública.

Em 2018 os hospitais de Macau disponibilizavam 1604 camas de internamento, ou seja, mais oito face a 2017. Estiveram internados 60000 doentes $(+2,2 \%$, em termos anuais), por um período médio de 7,2 dias (+0,2 dias). A taxa de utilização das camas de internamento $(74,4 \%)$ cresceu $3,6 \%$, em termos anuais, devido aos acréscimos quer dos doentes internados quer da duração média do internamento, informam os serviços de Estatística e Censos. ${ }^{6}$

Foram atendidos 1788000 indivíduos nas consultas externas dos hospitais, mais 5,3\%, em relação a 2017. Realça-se

\section{REFERÊNCIAS}

1. Boletim Oficial de Macau. Decreto Lei n. ${ }^{\circ}$ 10/2010. [consultado 2019 set 21]. Disponível em: https://bo.io.gov.mo/bo/i/2010/36/lei10.asp.

2. Government of Macao Special Administrative Region. Statistics and Census Service. Estatísticas do Turismo. [consultado 2019 ago 27]. Disponível em: https://www.dsec.gov.mo/Statistic.aspx?lang=en-US\& NodeGuid=7b23463a-d253-4750-bd12-958030df5ccb.

3. The Australian Council on Healthcare Standards. Member Organizations List. [consultado 2019 ago 27]. Disponível em: https://www.achs.org.au/ members/member-organisations-list/\#MACAU.

4. Academia Médica de Macau. O procedimento de admissão dos membros iniciais da Academia Médica de Macau. [consultado 2019 que as consultas de Medicina Interna totalizaram 285 000, ou seja $15,9 \%$ do total, seguindo-se as de Medicina Física e de Reabilitação (247 000) e Cirurgia Geral (197 000), as quais representaram $13,8 \%$ e $11,0 \%$ do total, respectivamente.

De acordo com os dados administrativos de 2018 fornecidos pelos Serviços de Saúde, existiam em Macau 1754 médicos $(+1,4 \%$, face a 2017$)$ e 2464 enfermeiros $(+2,8 \%)$. O rácio foi 2,6 médicos por 1000 habitantes e 3,7 enfermeiros por 1000 habitantes. $^{7}$

Havendo ainda um déficit entre a formação de especialistas e as necessidades do território, mantém-se o regime de contratação de especialistas ao exterior, maioritariamente provenientes da RPC e Portugal. Nos últimos tempos assistiu-se à contratação de mais especialistas originários da RPC do que de Portugal o que também contribui para a referida heterogeneidade da cultura médica que tem de ser harmonizada no dia a dia. Apraz assinalar que este ano foram contratados em Portugal cerca de 10 especialistas no total para diferentes áreas. O número de especialistas a serem recrutados no exterior varia de acordo com a necessidade de especialistas nas diferentes áreas. Contudo, a abertura de recrutamento nem sempre traduz uma resposta significativa, ficando as vagas por serem ocupadas.

A RPC definiu para esta zona um programa de desenvolvimento que designa de "A Grande Baía da China" apontando a Macau e Hong Kong o caminho do desenvolvimento económico integrando uma área com 80 milhões de habitantes (HK tem cerca de oito milhões). Este programa vai influenciar Macau no plano de desenvolvimento económico, e inevitavelmente no que diz respeito à Saúde. Não há ainda indicadores claros para análise mas fica aqui o apontamento para seguir com atenção. ${ }^{8}$

Tendo o privilégio de pertencer à Equipa de Supervisão da Formação Médica da AMM tenho visto o esforço constante e o sentido de responsabilidade incutido no espírito de todos os envolvidos na construção desse projeto. Acredito que a qualidade da formação médica no território irá sofrer uma melhoria substancial e espero que a Medicina Portuguesa continue a dar o seu contributo tanto na formação pré como pós-graduada, na formação de jovens médicos especialistas colaborando essencialmente como orientadores de formação, transmitindo experiência e know-how, participando em cursos de formação e nas reuniões científicas como preletores e moderadores.

\section{CONFLITO DE INTERESSES}

Nenhum conflito de interesse a declarar.

set 21]. Disponível em: http://www.am.gov.mo/index_pt.html,

5. Boletim Oficial de Macau. Decreto-Lei n. ${ }^{\circ}$ 17/88/M. [consultado 2019 set 21]. Disponível em: https://bo.io.gov.mo/bo/i/88/10/declei17.asp.

6. Serviços de Estatística da Saúde. Estatísticas da Saúde. Macau: SES; 2019.

7. Direcção de Estatística e Censos de Macau. Estatísticas. [consultado 2019 set 21]. Disponível em: http://www.dsec.gov.mo.

8. Guandong - Hong Kong. - Macau Greater Bay Area plan. [consultado 2019 set 21]. Disponível em: https://www.bayarea.gov.hk/en/home/ index.html. 